\title{
Membangun sikap kerukunan sosial melalui kerukunan internal dalam jemaat: Refleksi teologis 1 Korintus 1:10-13
}

\author{
Asih Rachmani Endang Sumiwi ${ }^{1}$, Joko Sembodo ${ }^{2}$, Joseph Christ Santo ${ }^{3}$ \\ 1,2.3 Sekolah Tinggi Teologi Torsina, Surakarta, Jawa Tengah \\ Correspondence: asihres@gmail.com
}

https://orcid.org/00000002-0039-0155

\section{Keywords:}

1 Corinthians 10; church harmony; congregational harmony; social harmony;

1 Korintus 10; kerukunan jemaat; kerukunan sosial

\section{Article History}

Submitted: July 19, 2021

Revised: August 25, 2021

Accepted: Sept. 21, 2021

DOI: https://doi.org/ 10.30995/kur.v7i2.339

Copyright: @2021, Authors. License:

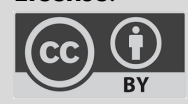

Scan this QR, Read Online

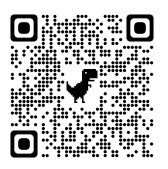

Abstract: Harmony in society is an important thing that needs to be realized as an effort to suppress conflict with the nuances of SARA (ethnicity, religion, race, inter-group). The church needs to have sensitivity in contributing to realizing this harmony. Starting from the internal harmony of Christians, this harmony extends to social harmony. This article seeks to answer how Christians realize social harmony with regard to Paul's message on 1 Corinthians 1:10-13. This research was conducted with a qualitative literature approach, using an interpretive descriptive method on the text of 1 Corinthians 1: 10-13. The conclusion of this paper is that Christians need to participate in building social harmony starting from the internal harmony of the congregation, which is done in three ways: speaking the same things, which means having agreement; being closely united, which means being bound together; and having one mind, which means having similarities in thinking and considering

Abstrak: Kerukunan dalam bermasyarakat merupakan hal penting yang perlu diwujudkan sebagai upaya untuk menekan konflik dengan nuansa SARA. Gereja perlu memiliki sensitivitas dalam turut mewujudkan kerukunan tersebut. Diawali dari kerukunan intern umat Kristen, kerukunan ini meluas kepada kerukunan sosial. Artikel ini berusaha menjawab bagaimana orang Kristen mewujudkan kerukunan sosial berkenaan dengan pesan Paulus melalui 1 Korintus 1:10-13. Penelitian ini dilakukan dengan pendekatan kualitatif literatur, menggunakan metode deskriptif interpretatif atas teks 1 Korintus 1:10-13. Kesimpulan dari tulisan ini adalah orang Kristen perlu turut membangun kerukunan sosial, yang dimulai dari kerukunan internal jemaat, dengan menerapkan tiga hal, yaitu seia sekata, yang berarti memiliki kesepakatan; erat bersatu, yang berarti terikat bersama; dan sehati sepikir, yang berarti memiliki kesamaan dalam berpikir dan mempertimbangkan.

\section{Pendahuluan}

Indonesia merupakan negara kesatuan yang bersifat pluralistis, baik secara suku dan ras, budaya, dan agama. Keberagaman merupakan hakikat dari bangsa ini yang masih kerap sulit diaktualisasikan dalam kehidupan berbangsa. Seringnya muncul konflik dengan nuansa SARA menunjukkan bahwa realitas pluralistis bangsa ini masih mengalami disrupsi. Namun demikian, tidak sedikit elemen bangsa ini terus mengupayakan terciptanya kerukunan hidup di antara anak bangsa. Demikian juga gereja, harus memiliki sensitivitas dalam membangun kerukunan sosial di lingkungannya sebagai bagian dari menciptakan kerukunan hidup bangsa. 
Dalam pengertian umum, kerukunan berasal dari kata "rukun" yang berarti: baik dan damai, tidak bertengkar, bersatu hati, bersepakat. ${ }^{1}$ Dalam arti yang lebih khusus, Wirutomo, seorang guru besar sosiologi, memberikan definisi, "kerukunan adalah menciptakan integrasi sosial dalam masyarakat melalui konsep-konsep tertentu dalam upaya mempersatukan makhluk sosial, baik secara individu maupun kelompok untuk memberikan rasa kenyamanan dan ketenteraman." ${ }^{2}$ Kerukunan sosial yang dimaksud yang dimaksud oleh peneliti adalah kerukunan yang terjadi pada lingkup masyarakat yang bersifat pluralistis. Gereja harus dapat menjalankan fungsinya sebagai garam dan terang di tengah masyarakat, sehingga memelihara kerukunan menjadi sesuatu yang dapat disebut sebagai tanggung jawabnya. Namun, menciptakan hingga memelihara kerukunan bukanlah sesuatu yang mudah, sehingga hal tersebut harus dibiasakan dalam kehidupan jemaat. Artinya, kerukunan sosial harus dapat dimulai dari menciptakan kerukunan umat atau jemaat.

Salah satu nasihat terkait hal kerukunan atau rukun dilakukan oleh Paulus kepada di jemaat Korintus, "Tetapi aku menasihatkan kamu...supaya kamu seia sekata dan jangan ada perpecahan di antara kamu, tetapi sebaliknya supaya kamu erat bersatu dan sehati sepikir" (1Kor. 1:10-13). Nasihat ini muncul di bagian awal suratnya kepada jemaat Korintus, mengindikasikan betapa persoalan perpecahan menjadi isu besar yang sedang melanda jemaat tersebut. Berbagai kelompok telah memilih tokoh tertentu untuk diikuti, daripada bersatu dalam nama Yesus. Godaan untuk mengikuti pemimpin rohani manusia ada di setiap zaman dan tak dapat dipungkiri hal ini mengakibatkan perpecahan di antara tubuh Kristus. ${ }^{3}$

Isu tentang kerukunan telah banyak dikaji sebagai kajian sosial dan agama. Ismail meneliti posisi agama dalam kerukunan sosial pada beberapa kelompok masyarakat, dan mengemukakan bahwa terbentuknya ruang kerukunan hanya akan terjadi ketika budaya masyarakat mampu menciptakan sarana pertemuan di luar konteks agama. ${ }^{4}$ Di sisi lain, Ghazali mengkaji kerukunan dalam perspektif Islam, bahwasanya Islam memiliki ajaran tentang kerukunan yang merupakan salah satu bentuk aktualisasi dari doktrin Islam tentang tasamuh (toleransi). ${ }^{5}$ Dalam pendekatan serupa tetapi dengan sudut pandang yang berbeda Arifianto dan Santo mengkaji kerukunan dalam perspektif iman Kristen, bahwasanya keberadaan orang Kristen di tengah masyarakat yang plural adalah untuk menjadi garam dan terang. ${ }^{6}$ Isu kerukunan menjadi penting, sehingga kerukunan antar agama pun menjadi kajian yang tidak lepas dari membangun kerukunan sosial. ${ }^{7} \mathrm{Me}-$ lengkapi kajian Mawardi, Haryanto menyimpulkan kearifan lokal sebagai instrumen penting dalam kerukunan beragama. ${ }^{8}$ Dari perspektif Kristen, kajian yang dilakukan oleh Kawangung dan Jeni Ishak Lele menunjukkan pentingnya membangun kerukunan sosial. ${ }^{9}$ Arifianto dan Stevanus masih terpaut pada pentingnya membangun kerukunan beragama yang berimplikasi pada kegiatan misi. ${ }^{10}$ Kajian ini berbeda dengan apa yang dilakukan oleh Kawangung, atau Arifianto dan Stevanus, yang memokuskan pada kerukunan beragama. Kajian yang dilakukan di

1 "rukun," Kamus Besar Bahasa Indonesia, 2016.

${ }^{2}$ Paulus Wirutomo, Sistem Sosial Indonesia (UI Press, 2012).

${ }^{3}$ Deborah Burrus, Corinthians, Ephesians, and Philippians (Book 1, Lessons 1|10) (Dickson, TN: Explorer's Bible Study, 2005), 10.

${ }^{4}$ Arifuddin Ismail, "Refleksi Pola Kerukunan Umat Beragama," Analisa 17, no. 2 (2010): 175.

${ }^{5}$ Adeng Muchtar Ghazali, "Teologi Kerukunan Beragama dalam Islam (Studi Kasus Kerukunan Beragama di Indonesia)," Analisis XIII, no. 2 (2013): 281-302.

${ }^{6}$ Yonatan Alex Arifianto dan Joseph Christ Santo, "Tinjauan Trilogi Kerukunan Umat Beragama Berdasarkan Perspektif Iman Kristen," Angelion: Jurnal Teologi dan Pendidikan Kristen 1, no. 1 (2020): 1-14.

7 Mawardi, "Reaktualisasi Kerukunan Antar Umat Beragama Dalam Kemajemukan Sosial," Substantia 17, no. April (2015): 55-66.

${ }^{8}$ Joko Tri Haryanto, "Kearifan Lokal Pendukung Kerukunan Beragama pada Komuntias Tengger Malang Jatim," Analisa 21, no. 2 (2014): 201.

${ }^{9}$ Yudhi Kawangung dan Jeni Ishak Lele, "Diskursus Kerukunan Sosial Dalam Perspektif Masyarakat Kristen Di Indonesia," VISIO DEI: Jurnal Teologi Kristen 1, no. 1 (2019): 141-160.

${ }^{10}$ Yonatan Alex Arifianto dan Kalis Stevanus, "Membangun Kerukunan Antarumat Beragama dan Implikasinya bagi Misi Kristen," HUPERETES: Jurnal Teologi dan Pendidikan Kristen 2, no. 1 (2020): 39-51. 
sini lebih luas dari sekadar kerukunan beragama, karena berbicara pada tatanan sosial yang menginklusi banyak isu, seperti budaya, suku, dan persoalan sosial lainnya.

Kajian ini bertujuan untuk menunjukkan betapa pentingnya membangun dan menciptakan kerukunan dalam jemaat, seperti nasihat Paulus dalam 1 Korintus 1:1-13, agar menjadi spiritualitas yang menjadikan orang percaya suka hidup rukun, termasuk dalam lingkup sosial masyarakat.

\section{Metode Penelitian}

Kajian ini adalah sebuah penelitian pendekatan kualitatif literatur ${ }^{11}$, dengan menggunakan metode deskriptif interpretatif atas teks 1 Korintus 1:10-13. ${ }^{12}$ Teks tersebut dianalisis berdasarkan makna kata dan strukturnya, juga berdasarkan konteksnya. Dengan menelusuri konteks jemaat pada saat surat 1 Korintus ditulis dapat diketahui bahwa jemaat Korintus ada dalam perpecahan dan ditandai dengan timbulnya golongan-golongan. Dengan demikian penggunaan nas 1 Korintus 1:10-13 dipandang sesuai dalam mewujudkan semangat kerukunan, sebagaimana Paulus menasihatkan agar jemaat Korintus tetap "seia sekata, erat bersatu, dan sehati sepikir." Ketiga frasa tersebut menjadi kriteria untuk terciptanya kerukunan internal jemaat, bahwa Paulus menginginkan agar jemaat Korintus hidup dalam kerukunan. Selanjutnya dilakukan perluasan penerapan ketiga frasa tersebut untuk membangun kerukunan dalam hidup bermasyarakat, yaitu komitmen orang Kristen untuk seia sekata, erat bersatu, dan sehati sepikir dalam hidup bermasyarakat.

\section{Pembahasan}

\section{Munculnya Golongan-golongan dalam Jemaat Korintus}

Surat 1 Korintus diawali dengan keprihatinan Paulus atas terjadinya perpecahan di antara jemaat Korintus. Salah satu tujuan utama surat ini adalah untuk memperbaiki kejahatan yang telah muncul di gereja Korintus, rasul pertama-tama menunjukkan perpecahan yang ada. la menasihati para anggota gereja itu untuk bersatu. ${ }^{13}$ Pengidolaan pemimpin menjadi pemicu perpecahan di jemaat Korintus. ${ }^{14}$ Bahkan di antara mereka saling mengunggulkan pemimpin mereka masingmasing. Mereka mengelompokkan diri sesuai dengan pemimpin yang disukai dan kemudian mereka saling membanggakan pemimpin-pemimpin tersebut. Berdasarkan informasi yang diterima dari Kloe, jemaat Korintus terbagi ke dalam golongan Apolos, golongan Kefas, golongan Paulus dan golongan Kristus. Golongan Apolos terdiri dari kaum filsuf yang mengikuti pandangan Yunani, golongan Kefas terdiri dari kaum legalistik yang terdiri dari orang Yahudi dan bukan Yahudi yang takut akan Tuhan sebelum masuk Kristen, golongan Paulus terdiri dari kaum Libertin, mereka mendengar khotbah Paulus tentang kemerdekaan Kristen yang menyimpulkan bahwa mereka dapat hidup seenaknya, dan golongan Kristus terdiri dari kaum mistik yang menekankan hal-hal supraalami. ${ }^{15}$ Keprihatinan Paulus ini ditulis sampai diulang dua kali, di dalam 1 Korintus pasal 1 dan pasal 3.

Berkembangnya pelayanan di Korintus menyebabkan beberapa pemimpin dari golongan Apolos, golongan Kefas dan golongan Paulus mulai menonjol. Walaupun mereka sama-sama pelayan Injil, hati jemaat Korintus lebih melekat kepada figur pelayan Injil tersebut daripada Injil

\footnotetext{
${ }^{11}$ Sonny Eli Zaluchu, "Metode Penelitian di dalam Manuskrip Jurnal Ilmiah Keagamaan," Jurnal Teologi Berita Hidup 3, no. 2 (2021): 249-266.

12 Joseph Christ Santo, "Strategi Menulis Jurnal Ilmiah Teologis Hasil Eksegesis," in Strategi Menulis Jurnal untuk Ilmu Teologi (Semarang: Golden Gate Publishing, 2020), 121-139.

${ }^{13}$ Charles Hodge, An Exposition of the First Epistle to the Corinthians (Bellingham, WA: Logos Research Systems, Inc., 2009), 11.

${ }^{14}$ Asih Rachmani Endang Sumiwi dan Yonatan Alex Arifianto, "Tinjauan Roma 15:5-6 untuk Meningkatkan Kerukunan Intern Orang Percaya Masa Kini," Jurnal Teologi Berita Hidup 3, no. 2 (2021): 267-283.

${ }^{15}$ John Drane, Memahami Perjanjian Baru (Jakarta: BPK Gunung Mulia, 2000), 352.
} 
itu sendiri. ${ }^{16}$ Paulus adalah rasul orang-orang bukan Yahudi dan Petrus dari orang-orang Yahudi (Gal. 2:8), kemungkinan besar orang-orang Yahudi yang bertobat meminta otoritas Petrus. Namun, orang-orang non-Yahudi yang bertobat, tidak bersatu di antara mereka sendiri. Beberapa orang berkata, "Kami pengikut Paulus," yang lain berkata, "Kami pengikut Apolos."17 Paulus menekankan bahwa setiap tokoh yang mereka idolakan adalah sama-sama pekerja Allah dengan spesifikasi tugas masing-masing. Perbedaan peran mereka dalam pelayanan bukan untuk diperdebatkan. Paulus memberikan gambaran dirinya menanam, dan Apolos menyiram. Pekerja yang menanam dan pekerja yang menyiram memiliki kekhasan masing-masing. Tetapi di dalam kekhasan tersebut ada yang tidak boleh dilupakan bahwa sentralnya adalah Kristus. Paulus mengatakan bahwa Kristuslah yang memberikan pertumbuhan bagi tanaman yang ditanam dan disiram tersebut. Sesungguhnya, secara implisit, Paulus ingin menjelaskan bahwa tidak ada perbedaan golongan di dalam Kristus. Kristus satu untuk semua, Kristus tidak dibagi-bagi menurut orang yang memberitakan Injil-Nya. Pada masa sekarang pun, potensi perpecahan jemaat sangat mungkin terjadi. Jemaat yang terdiri dari berbagai latar belakang dan karakter yang memiliki nilai-nilai yang berbeda dapat memicu terjadinya konflik.

Gereja masa kini kadang-kadang mengalami hal yang serupa. Terdapat anggota jemaat yang memiliki hamba Tuhan favorit. Tanpa disadari, di dalam gereja terjadi kelompok-kelompok di mana masing-masing kelompok memiliki idola masing-masing. Salah satu peneliti menjadi saksi salah satu perpecahan gereja yang disebabkan pengidolaan pemimpin jemaat. ${ }^{18}$ Pada sekitar tahun 1980 terjadi perpecahan pada Gereja Bethel Indonesia (GBI) jemaat Ngagel Madya Surabaya yang digembalakan oleh Pdt. Jusuf Tiost. Alex Tanuseputra, salah satu tokoh dalam jemaat tersebut, menjadi favorit sebagian jemaat karena menekankan lagu-lagu baru dalam persekutuan doa yang diselenggarakan di rumahnya. Dengan dukungan sebagian jemaat, Alex Tanuseputra memisahkan diri dari GBI Ngagel Madya dan mendirikan GBI Manyar, yang di kemudian hari bertumbuh pesat dan menjadi sinode Gereja Bethany Indonesia.

Benih-benih perpecahan perlu diatasi sejak dini demi mewujudkan kerukunan jemaat. Gereja yang mulai mengidolakan bahkan mengkultuskan hamba Tuhan membuka peluang bagi terjadinya perpecahan, dan tidak bisa menjadi saksi di muka bumi ini. Perpecahan tidak menjadi kesaksian yang baik, karena orang yang belum mengenal Kristus menjadi tersandung ketika melihat karakter jemaat Tuhan yang tidak mencerminkan karakter Kristus.

\section{Kerukunan dalam 1 Korintus 1:10-13}

Paulus mengirimkan surat kepada jemaat Korintus dengan maksud merespons persoalan yang sedang terjadi di dalam jemaat. Paulus menghendaki konflik yang sedang terjadi di jemaat Korintus segera diatasi. Pada hakikatnya konflik adalah perselisihan antar kelompok atau perorangan, perselisihan ini disebabkan perbedaan kepentingan dalam jemaat. Konflik terjadi karena masing-masing pihak mempertahankan nilai-nilai yang dianggap benar, dan pada sisi lain mendesak pihak yang berbeda untuk mengikuti nilai-nilai tersebut. ${ }^{19}$ Konflik antarpemimpin jemaat bukan saja terjadi pada jemaat Korintus, menjelang perjalanan misi kedua pun sempat terjadi konflik yang berdampak pada pelayanan Paulus dan Barnabas. ${ }^{20}$

Sebagai respons terhadap terjadinya konflik di Korintus, Paulus mengatakan, "Tetapi aku menasihatkan kamu...supaya kamu seia sekata...supaya kamu erat bersatu dan sehati sepikir" (1Kor. 1:10). Dalam nasihat ini terkandung tiga hal untuk menyelesaikan perselisihan jemaat Korintus, yaitu seia sekata, erat bersatu, dan sehati sepikir.

\footnotetext{
${ }^{16}$ Alkitab Penuntun Hidup Berkelimpahan (Malang: Gandum Mas, 2016), 1879.

${ }^{17}$ Charles Hodge, 1 Corinthians, The Crossway classic commentaries (Wheaton, III.: Crossway Books, 1995), 1Co. 1:12.

${ }^{18}$ Joseph Christ Santo saksi terjadinya perpecahan antara Jusuf Tiost dan Alex Tanuseputra.

${ }^{19}$ Joseph Christ Santo, "Makna Kesatuan Gereja dalam Efesus 4: 1-16," Jurnal Teologi El-Shadday 4, no. 2 (November 30, 2017): 1-34, http://stt-elshadday.ac.id/e-journal/index.php/jte/article/view/2.

${ }^{20}$ Sonny Eli Zaluchu, "Analisis Kisah Para Rasul 15 Tentang Konflik Paulus dan Barnabas serta Kaitannya dengan Perpecahan Gereja," Kurios 4, no. 2 (2918): 107-117, http://www.sttpb.ac.id/e-journal/index.php/kurios.
} 


\section{Seia Sekata dalam Hidup Berjemaat}

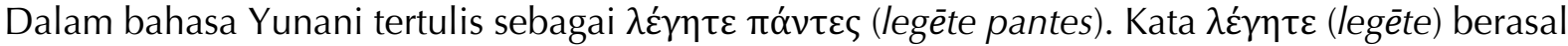

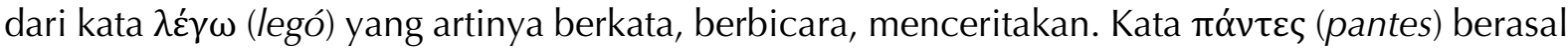

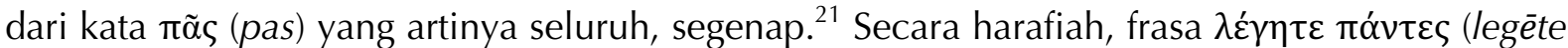
pantes) memiliki arti "semua berkata-kata sama", yang dalam bahasa Indonesia diterjemahkan "seia sekata". Frasa ini mengandung pengertian adanya pernyataan yang sama atau ikrar yang diucapkan bagi sebuah kebersamaan. Istilah lain yang dapat digunakan adalah kesepakatan, Paulus menghendaki jemaat Korintus memiliki kesepakatan. Jemaat yang seia sekata adalah jemaat yang membangun kata sepakat di dalam hubungan internal jemaat.

\section{Erat Bersatu dalam Hidup Berjemaat}

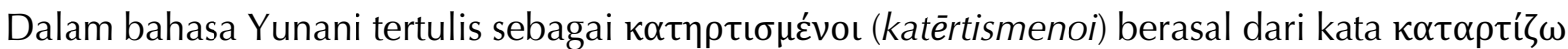
(katartizó) yang artinya terikat bersama, terpadu. ${ }^{22}$ Dengan demikian dapat diartikan bahwa erat bersatu berarti terikat bersama, terpadu. Erat artinya tidak mudah dilepaskan, tidak mudah dipisahkan. Hubungan yang erat adalah hubungan di mana orang-orang yang terhubung tersebut tidak ingin dilepaskan. Jemaat yang erat bersatu adalah jemaat yang kesatuannya tidak mudah dicerai-beraikan. Kesatuan yang erat dapat terwujud ketika masing-masing anggota jemaat tidak memandang perbedaan di antara mereka sebagai hal yang dapat memisahkan, sebaliknya dengan perbedaan tersebut mereka saling melengkapi dan tidak ingin dipisahkan.

Pada bagian lain dari kitab ini Rasul Paulus memberikan gambaran kesatuan dalam perbedaan melalui ilustrasi tubuh dan anggota-anggotanya (1Kor. 12). Masing-masing anggota tubuh memiliki kekhasan sehingga berbeda satu dengan lainnya, tetapi setiap anggota tubuh itu saling terikat dalam kesatuan. Anggota tubuh yang tidak terikat dengan tubuh tidak dapat disebut bagian dari tubuh. Ini berarti kesatuan tidak identik dengan keseragaman; kesatuan adalah ketika masing-masing anggota jemaat dengan kekhasannya mau bersatu dengan anggota jemaat lain yang berbeda.

\section{Sehati Sepikir dalam Hidup Berjemaat}

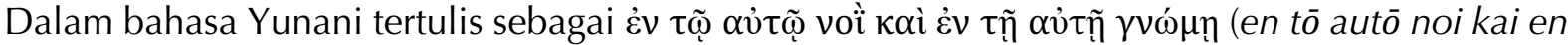

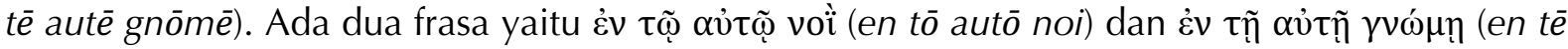
autē gnōmēe). Kata voî̀ (noi) berasal dari voṽs (nous) yang berarti pikiran atau akal budi. Kata

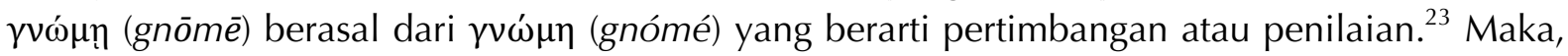
yang dimaksud sehati sepikir adalah memiliki kesamaan dalam berpikir dan dalam mempertimbangkan sesuatu.

Paulus mendesak jemaat Korintus menggunakan pikiran dan pertimbangan dalam memahami kebenaran. Mereka perlu menundukkan kepentingan pribadi dan kesukaan pribadi di bawah kebenaran. Artinya, ketika ada perbedaan di antara mereka, maka mereka perlu duduk bersama kembali kepada kebenaran Allah. Dengan menundukkan pada kebenaran Allah, maka ketika yang pendapatnya benar perlu merangkul yang berpendapat keliru, sebaliknya yang berpendapat keliru tidak bersikukuh mempertahankan pendapatnya.

Nasihat serupa ditujukan Rasul Paulus kepada jemaat Filipi, bahwa untuk mewujudkan kerukunan mereka harus memiliki pikiran dan perasaan yang terdapat juga dalam Kristus Yesus (Flp. 2:5). Ketika masing-masing anggota jemaat sejalan dengan perasaan Kristus, mereka ada dalam kondisi yang disebut sehati dengan Kristus; demikian pula ketika sejalan dengan pikiran Kristus, mereka disebut sepikir dengan Kristus. Itu sebabnya, agar setiap anggota jemaat bisa sehati sepikir, maka masing-masing perlu mengadopsi perasaan dan pikiran Kristus Sang pemimpin tertinggi jemaat.

\footnotetext{
${ }^{21}$ Hebrew/Greek Interlinear Bible, V28-b21012 ed. (HagiosTech, Inc. All rights reserved, 2021).

22 lbid.

${ }^{23}$ Ibid.
} 


\section{Mengupayakan Kerukunan Sosial}

Pada masa sekarang orang percaya perlu menguasai diri untuk hidup rukun dengan bukan saja dengan sesama orang percaya. Apabila seorang Kristen sudah terbiasa membangun kerukunan internal jemaat maka selanjutnya adalah menerapkan kerukunan di tengah masyarakat. Orang yang sudah terbiasa membangun kerukunan dengan orang-orang seiman yang ada di dekatnya, maka baginya akan lebih mudah membangun kerukunan dalam komunitas yang lebih luas. Salah satu bentuk kerukunan sosial adalah kerukunan antar-umat beragama. Tentang hal ini Suharto mengemukakan, bahwa kerukunan antar-umat beragama akan mudah terbina jika setiap umat beragama taat ajaran agamanya masing-masing. ${ }^{24}$ Dalam membangun kerukunan sosial, orang percaya perlu menerapkan ketiga nilai yang dinasihatkan Paulus untuk dimiliki jemaat Korintus.

\section{Seia Sekata dalam Hidup Bermasyarakat}

Dalam hal seia sekata, orang Kristen perlu memiliki kata sepakat bersama masyarakat sekitar terkait dengan kebangsaan Indonesia. Seia sekata memampukan kelompok yang berbeda latar belakang bisa duduk bersama. Di dalam Alkitab dicontohkan adanya Matius dan Simon orang Zelot yang bisa duduk bersama sebagai murid Yesus (Mat. 10:1-4). Kedua murid ini mewakili kelompok yang berseberangan. Matius berlatar pemungut cukai yang bekerja memungut pajak dari orang-orang Yahudi bagi penjajah Romawi; sebaliknya Simon orang Zelot adalah pejuang nasionalisme yang melawan penjajah Romawi demi mendapatkan kemerdekaan. Tetapi mereka memiliki kata sepakat karena tujuan yang sama, yaitu menjadi murid Yesus.

Bagi bangsa Indonesia, kesepakatan ini sudah diawali pada tahun 1928 oleh pemuda-pemuda Indonesia melalui ikrar yang disebut Sumpah Pemuda. Awalnya di wilayah jajahan Belanda ada berbagai macam etnis yang masing-masing menganggap diri sebagai sebuah bangsa. Tapi melalui Sumpah Pemuda, beragam etnis itu dilebur menjadi satu bangsa, yaitu bangsa Indonesia. Kesepakatan ini membawa dampak yang besar, yaitu bersatunya perjuangan kemerdekaan menjadi satu kekuatan besar yang ketika tiba saatnya menghasilkan kemerdekaan dari penjajahan Belanda.

Semangat Sumpah Pemuda yang telah diikrarkan hampir seabad lalu perlu dijaga demi eksistensi Indonesia. Bangsa dan negara Indonesia yang memiliki berbagai keragaman di dalamnya harus tetap seia sekata agar tetap eksis. Di tengah bangsa yang telah memiliki kesepakatan agung ini peran orang Kristen sebagai warganegara perlu diwujudkan dalam menjaga komitmen tersebut dengan jalan tidak membeda-bedakan etnis atau golongan yang ada di Indonesia. Maka dalam mewujudkan prinsip seia sekata, orang Kristen perlu mengedepankan kesatuan bangsa di atas kepentingan pribadi atau golongan.

\section{Erat Bersatu dalam Hidup Bermasyarakat}

Nilai-nilai yang diwariskan leluhur bangsa Indonesia mengakui adanya kesatuan di tengah keberagaman. Semboyan "Bhinneka Tunggal Ika" yang tertera pada lambang negara Garuda Pancasila diambil dari kitab Sutasoma, karya leluhur bangsa Indonesia pada abad ke-14. Semboyan ini memiliki arti "berbeda-beda tetapi tetap satu." Pada awalnya kalimat ini ditujukan kepada Siwa dan Budha, simbol dari keyakinan yang berbeda, tapi kemudian semboyan ini dipakai untuk menggambarkan Indonesia yang memiliki keragaman dalam banyak segi. ${ }^{25}$ Bapak-bapak pendiri bangsa Indonesia telah mengangkat semboyan kuno ini untuk dijadikan semboyan pemersatu bangsa Indonesia.

Prinsip kesatuan dalam keberagaman dipahami dalam iman Kristen dengan gambaran kesatuan tubuh dengan beraneka ragam anggota. Anggota-anggota tubuh, sekalipun masing-masing

\footnotetext{
${ }^{24}$ Sugeng Suharto, Kebijakan Pemerintah sebagai Manifestasi Peningkatan Toleransi Umat Beragama guna Mewujudkan Stabilitas Nasional dalam Rangka Ketahanan Nasional (Ponorogo: REATIV, 2019).

${ }^{25}$ Widya Lestari Ningsih, "Kitab Sutasoma: Pengarang, Isi, dan Bhinneka Tunggal," ed. Nibras Nada Nailufar, Kompas.com, Mei 6, 2021, https://www.kompas.com/stori/read/2021/05/06/150410179/kitab-sutasoma-pengarangisi-dan-bhinneka-tunggal-ika?page=all.
} 
memiliki kekhasan yang menjadikan berbeda dari yang lainnya, adalah bagian dari tubuh yang satu (1Kor. 12:12-27). Paulus telah mengajarkan bahwa dalam kesatuan gereja terdapat keragaman karunia. Ini diilustrasikan dengan merujuk kepada tubuh manusia. Tubuh manusia adalah satu, namun terdiri dari banyak bagian; dan keragaman ini penting untuk persatuan. ${ }^{26}$ Pemahaman bahwa keberagaman tidak dapat diseragamkan ini dibutuhkan dalam membangun wawasan kesatuan. Bila orang Kristen membawa pemahaman ini dalam hidup bermasyarakat tentunya terbangun masyarakat yang erat bersatu tanpa mempermasalahkan perbedaan satu sama lain.

Dalam penerapan pemahaman ini untuk mewujudkan masyarakat yang erat bersatu, orang Kristen perlu mengakui adanya keberagaman yang sering kali disebut SARA (suku, agama, ras, dan antar golongan). Ketika orang Kristen memiliki semangat untuk erat bersatu, maka keberagaman bukanlah sesuatu yang perlu dipertajam sehingga menjadi perbedaan yang mengarah kepada perselisihan, sebaliknya keberagaman menjadi peluang untuk saling melengkapi sehingga terwujud kesatuan yang erat.

\section{Sehati Sepikir dalam Hidup Bermasyarakat}

Bila dalam hubungan internal gereja diperlukan sehati dan sepikir dengan Kristus sang kepala gereja, maka dalam hubungan berbangsa dan bernegara, orang Kristen perlu sejalan dengan apa yang dipikirkan pemerintah. Dalam surat Paulus kepada jemaat Roma, ditegaskan bahwa orang Kristen harus tunduk kepada pemerintah yang ada di atasnya. Perintah ini bukanlah hal yang mudah bagi orang-orang Kristen di Roma pada masa itu karena kaisar bukan orang yang percaya kepada Yesus Kristus. Tentunya hal ini berdampak pada keputusan-keputusan yang dibuat dan tindakan-tindakan yang diambil. Orang-orang Kristen di Roma harus menundukkan diri, artinya mau sejalan dengan keputusan yang ditetapkan kaisar.

Keberadaan orang-orang Kristen di Indonesia tidak sesukar orang-orang Kristen di kota Roma pada waktu itu. Pemerintah Indonesia adalah pemerintah yang memberikan kemerdekaan beragama bagi warga negara, dan keputusan-keputusan diambil dengan tujuan kesejahteraan bangsa Indonesia. Tidak ada alasan bagi orang-orang Kristen di Indonesia untuk menentang kebijakan pemerintah.

Orang Kristen perlu berusaha sejalan dengan program-program yang dijalankan pemerintah demi kemajuan bangsa. Memang tidak ada program yang sempurna karena pemerintah juga manusia yang penuh dengan kekurangan. Namun, sebagai terang yang harus menyala di tengah kegelapan, orang Kristen seharusnya memberikan teladan dalam hal mendukung program pemerintah, bukan menghalang-halangi seperti yang kadang-kadang dilakukan oleh sekelompok orang. Dalam hal inilah orang Kristen perlu sehati sepikir, sehingga kerukunan dapat terwujud, baik kerukunan internal jemaat maupun kerukunan sosial.

\section{KESIMPULAN}

Nasihat Paulus dalam 1 Korintus 1:10-13 agar jemaat hidup dalam kerukunan, menghindari perpecahan. Membangun kerukunan sosial dimulai dari membangun kerukunan internal jemaat yang dilakukan dengan tiga hal yaitu seia sekata yang berarti memiliki kesepakatan, erat bersatu yang berarti terikat bersama, dan sehati sepikir yang berarti memiliki kesamaan dalam berpikir dan mempertimbangkan. Orang Kristen yang sudah terbiasa membangun kerukunan dengan orang-orang seiman yang ada di dekatnya, maka baginya akan lebih mudah membangun kerukunan dalam komunitas yang lebih luas. Dalam hidup bermasyarakat orang Kristen dapat mewujudkan aspek seia sekata dengan menjaga semangat Sumpah Pemuda yang telah menyatukan Indonesia, mewujudkan aspek erat bersatu dengan mengedepankan semboyan Bhinneka Tunggal Ika, dan mewujudkan aspek sehati sepikir melalui dukungan yang diberikan kepada program-program pemerintah.

\footnotetext{
${ }^{26}$ Hodge, 1 Corinthians, The Crossway classic commentaries, 1Co. 12:12.
} 


\section{REFERENSI}

Arifianto, Yonatan Alex, dan Joseph Christ Santo. "Tinjauan Trilogi Kerukunan Umat Beragama Berdasarkan Perspektif Iman Kristen." Angelion: Jurnal Teologi dan Pendidikan Kristen 1, no. 1 (2020): 1-14.

Arifianto, Yonatan Alex, dan Kalis Stevanus. "Membangun Kerukunan Antarumat Beragama dan Implikasinya bagi Misi Kristen." HUPERETES: Jurnal Teologi dan Pendidikan Kristen 2, no. 1 (2020): 39-51.

Burrus, Deborah. Corinthians, Ephesians, and Philippians (Book 1, Lessons 1|10). Dickson, TN: Explorer's Bible Study, 2005.

Drane, John. Memahami Perjanjian Baru. Jakarta: BPK Gunung Mulia, 2000.

Ghazali, Adeng Muchtar. "Teologi Kerukunan Beragama dalam Islam (Studi Kasus Kerukunan Beragama di Indonesia)." Analisis XIII, no. 2 (2013): 281-302.

Haryanto, Joko Tri. "Kearifan Lokal Pendukung Kerukunan Beragama pada Komuntias Tengger Malang Jatim." Analisa 21, no. 2 (2014): 201.

Hodge, Charles. 1 Corinthians, The Crossway classic commentaries. Wheaton, Ill.: Crossway Books, 1995.

- An Exposition of the First Epistle to the Corinthians. Bellingham, WA: Logos Research Systems, Inc., 2009.

Ismail, Arifuddin. "Refleksi Pola Kerukunan Umat Beragama." Analisa 17, no. 2 (2010): 175.

Kawangung, Yudhi, dan Jeni Ishak Lele. "Diskursus Kerukunan Sosial Dalam Perspektif Masyarakat Kristen Di Indonesia." VISIO DEI: Jurnal Teologi Kristen 1, no. 1 (2019): 141160.

Mawardi. "Reaktualisasi Kerukunan Antar Umat Beragama Dalam Kemajemukan Sosial." Substantia 17, no. April (2015): 55-66.

Ningsih, Widya Lestari. "Kitab Sutasoma: Pengarang, Isi, dan Bhinneka Tunggal." Diedit oleh Nibras Nada Nailufar. Kompas.com, Mei 6, 2021.

https://www.kompas.com/stori/read/2021/05/06/150410179/kitab-sutasoma-pengarang-isidan-bhinneka-tunggal-ika?page=all.

Santo, Joseph Christ. "Makna Kesatuan Gereja dalam Efesus 4: 1-16." Jurnal Teologi El-Shadday 4, no. 2 (November 30, 2017): 1-34. http://stt-elshadday.ac.id/ejournal/index.php/jte/article/view/2.

_. "Strategi Menulis Jurnal IImiah Teologis Hasil Eksegesis." In Strategi Menulis Jurnal untuk Ilmu Teologi, 121-139. Semarang: Golden Gate Publishing, 2020.

Suharto, Sugeng. Kebijakan Pemerintah sebagai Manifestasi Peningkatan Toleransi Umat Beragama guna Mewujudkan Stabilitas Nasional dalam Rangka Ketahanan Nasional. Ponorogo: REATIV, 2019.

Sumiwi, Asih Rachmani Endang, dan Yonatan Alex Arifianto. "Tinjauan Roma 15:5-6 untuk Meningkatkan Kerukunan Intern Orang Percaya Masa Kini." Jurnal Teologi Berita Hidup 3, no. 2 (2021): 267-283.

Wirutomo, Paulus. Sistem Sosial Indonesia. UI Press, 2012.

Zaluchu, Sonny Eli. "Analisis Kisah Para Rasul 15 Tentang Konflik Paulus dan Barnabas serta Kaitannya dengan Perpecahan Gereja." Kurios 4, no. 2 (2918): 107-117. http://www.sttpb.ac.id/e-journal/index.php/kurios.

—. "Metode Penelitian di dalam Manuskrip Jurnal Ilmiah Keagamaan." Jurnal Teologi Berita Hidup 3, no. 2 (2021): 249-266.

Alkitab Penuntun Hidup Berkelimpahan. Malang: Gandum Mas, 2016.

Hebrew/Greek Interlinear Bible. V28-b21012 ed. HagiosTech, Inc. All rights reserved, 2021.

"rukun." Kamus Besar Bahasa Indonesia, 2016. 